\title{
COMPRESSIVE STRENGTH OF DAMAGED AND REPAIRED COMPOSITE PLATES
}

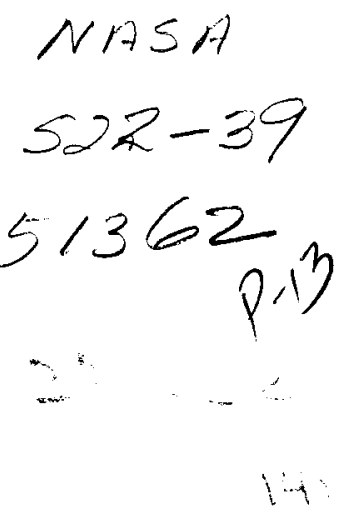

\begin{abstract}
Tests were performed assessing the effectiveness of repair in restoring the mechanical properties of damaged, solid composite plates made of Fiberite T300/976 graphite-epoxy. Some (75 percent) or all (100 percent) of the damaged zone was cut out, and the plate was repaired by plugging and patching the hole. The effectiveness of the repair was evaluated by measuring the compressive strengths of undamaged plates, damaged plates with no cutout, damaged plates with a cutout, and plates having been repaired.
\end{abstract}

\section{INTRODUCTION}

In this paper, data are presented showing the benefits, as represented by the in-plane compressive strength, which can be gained by repairing damaged composite plates. To this end, solid (as opposed to honeycomb) composite plates were subjected to impact or transverse static loads. Some or all of the damaged zone was removed, and the plate was then repaired. The in-plane compressive strengths of the plates were determined 1) prior to impact, 2) after impact, before repair, 3) after impact, with some or all of the damaged zone removed, and 4) after impact, with the damaged zone repaired.

These compressive strengths were then compared, and the effectiveness of the repair was assessed from these comparisons.

\section{EXPERIMENTS}

Four inches long and 3 inches wide plates made of Fiberite-T300/976 unidirectional graphiteepoxy tape were used in the tests. After manufacture, each plate was inspected by a pulse-echo ultrasonic technique (C-scan) to establish that they were undamaged. Damage was introduced in the plates in one of two ways. Either the plates were impacted with a projectile (impactor) fired from an air gun, or a transverse load was applied via an indenter and a mechanical tester. In both cases, the load was applied at the center of the plate by a hemispherical steel impactor (indenter) having a 0.25 inch radius. The damaged plates were inspected by X-ray and, some of the plates, also by pulse-echo Cscan. In this manner, the sizes of the damaged zones were determined.

The damaged zone was removed by grinding out an elliptical hole through the entire thickness of the plate (Figure 1). After grinding, the plate was again X-rayed to establish that the process did not damage the plate further. 

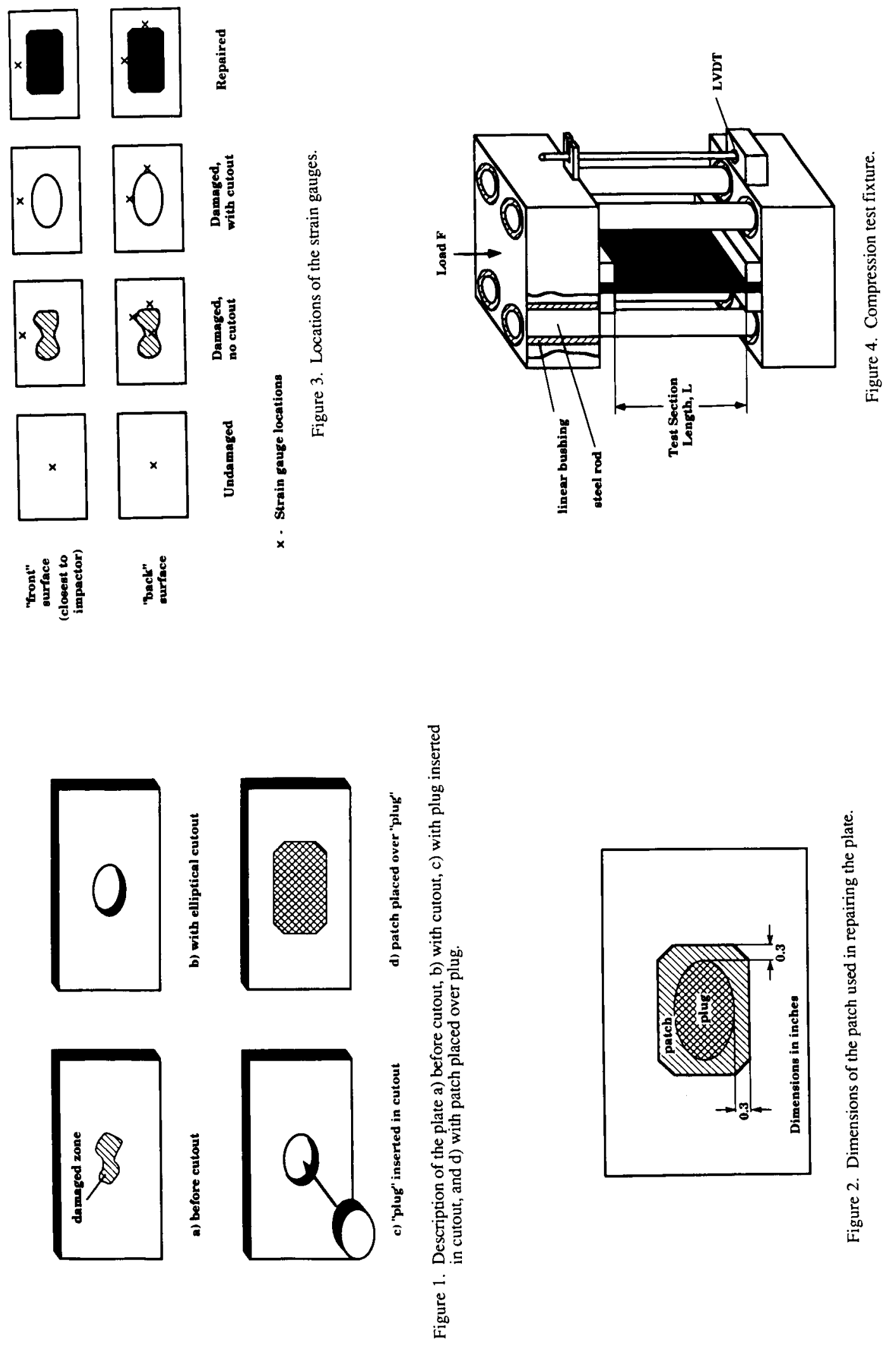
After holes were cut in the plates, the plates were repaired by placing a "plug" (made of the same material as the plate) in the hole (Figure 1). This plug had the same shape and size as the hole, and had the same layup as the plate. American Cyanamid FM300 adhesive was placed between the plug and the plate. One layer of Fiberite T300/976 graphite-epoxy cloth "patch" was placed above the plug on each side of the plate. The dimensions of the patch are given in Figure 2. The plates were vacuum bagged and cured. Strain gauges were then mounted on the plates (Figure 3 ).

The compressive strength of each plate was measured by clamping the two short edges of the plate in a specially built fixture (Figure 4). The compressive load was applied at a displacement rate of $2 \times 10^{-5} \mathrm{in} / \mathrm{sec}$, and the load versus strains and the load versus displacement were measured.

The following information was deduced from the data.

1) "Delamination buckling" load $F_{d b}$ is defined as the load at which the plate locally buckles above the damaged area. The load at which this occurs was determined from the output of the strain gauge placed at the center of the damaged region on the "back" surface.

2) "Damage growth" load $F_{g}$ is defined as the load at which the damaged area starts to grow. The load at which this occurs was determined from the strain gauges on the "back" surface of the plate located at the edge of the damaged area (plates without cutout), near the edge of the hole (plates with cutout), or near the edge of the repaired zone (repaired plates). The damage growth load data for plates with cutout or with repair were normalized with respect to the damage growth loads of damaged plates with no cutout $\mathrm{F}_{\mathrm{g}}{ }^{\mathrm{nc}}$.

3) "Buckling" load $F_{b}$ is defined as the load at which the entire plate buckles. The load at which this occurs was determined from the displacement and from the strain gauge on the "front" surface of the plate The buckling load data for damaged plates were normalized with respect to the buckling loads of undamaged plates $\mathrm{F}_{\mathrm{b}}{ }^{\mathrm{O}}$.

4) "Ultimate" load $F_{u}$ is defined as the maximum load which the plate can support before collapse. This load could be determined from any of the plots of load versus displacement or load versus strain. The ultimate load data for damaged plates were normalized with respect to the ultimate loads of the undamaged plates $\mathrm{F}_{\mathbf{u}}{ }^{\mathrm{O}}$.

\section{RESULTS}

The results presented below are grouped into four categories 1) delamination buckling load, $\mathrm{F}_{\mathrm{db}}$, 2) damage growth load, $F_{g}, 3$ ) buckling load, $F_{b}$, and 4) ultimate load, $F_{u}$. The measured loads are presented in terms of four variables, the number of plies $n$ in the $0^{\circ}$ ply groups, the mismatch angle $q$, and the initial damaged zone length $l_{D}$.

Below, data are presented for plates a) with no damage, b) with damage, c) with all (100\%) or some $(75 \%)$ of the damaged zone removed, and d) with the damaged zone repaired. For $100 \%$ of the damaged zone removed, the major axis of the elliptical cutout was equal to the maximum length of the damaged zone, and the minor axis was equal to the maximum width of the damaged zone. For $75 \%$ of the damaged zone removed, the above major and minor axes of the cutout ellipse were reduced to $75 \%$ of their original lengths. Obviously, in this case some of the damaged zone was not removed. All of the repaired plates had a $100 \%$ cutout before plugging and patching. 


\section{Delamination Buckling Load}

The measured delamination buckling loads are given in Figures 5-7. Data are only presented for damaged plates with no cutout or repair, as delamination buckling was not observed in the plates with cutout or repair.

The load (delamination buckling load $\mathrm{F}_{\mathrm{db}}$ ) at which a sublaminate in the damaged zone buckles increased as the number $\mathrm{n}$ of plies in the $0^{\circ}$ ply groups increased, i.e., as the thickness of the back ply group increased (Figure 5). This can be explained by observing that when the load was applied, the sublaminate below the damaged zone (at the "back" side of the plate) buckled. A thicker back ply group corresponds to a sublaminate which is stiffer and thus more resistant to buckling.

The delamination buckling load $F_{\mathrm{db}}$ decreased with mismatch angle $\mathrm{q}$ (Figure 6). To explain the reason for this, we observe that the data shown in this figure apply to plates in which the damage length was constant $\left(l_{D}=1.5\right.$ in), while the width was not controlled independently. In fact, the damage width $w_{D}$ (and consequently the damaged area) increased with the mismatch angle $q$ (Figure 6 ). Thus the size of the damaged area increased resulting in a decrease in the delamination buckling load $\mathrm{F}_{\mathrm{db}}$ with increasing mismatch angle $\mathrm{q}$.

The delamination buckling load $F_{d b}$ as a function of the initial damaged zone length $l_{D}$ is shown in Figure 7. For these $\left[04 / 90_{4}\right] \mathrm{s}$ plates, the width $w_{D}$ of the damaged zone was approximately equal to one half of the damage length $l_{D}$. As the length $l_{D}$ increased (and with it, the size of the damaged zone), the load required to buckle the sublaminate decreased.
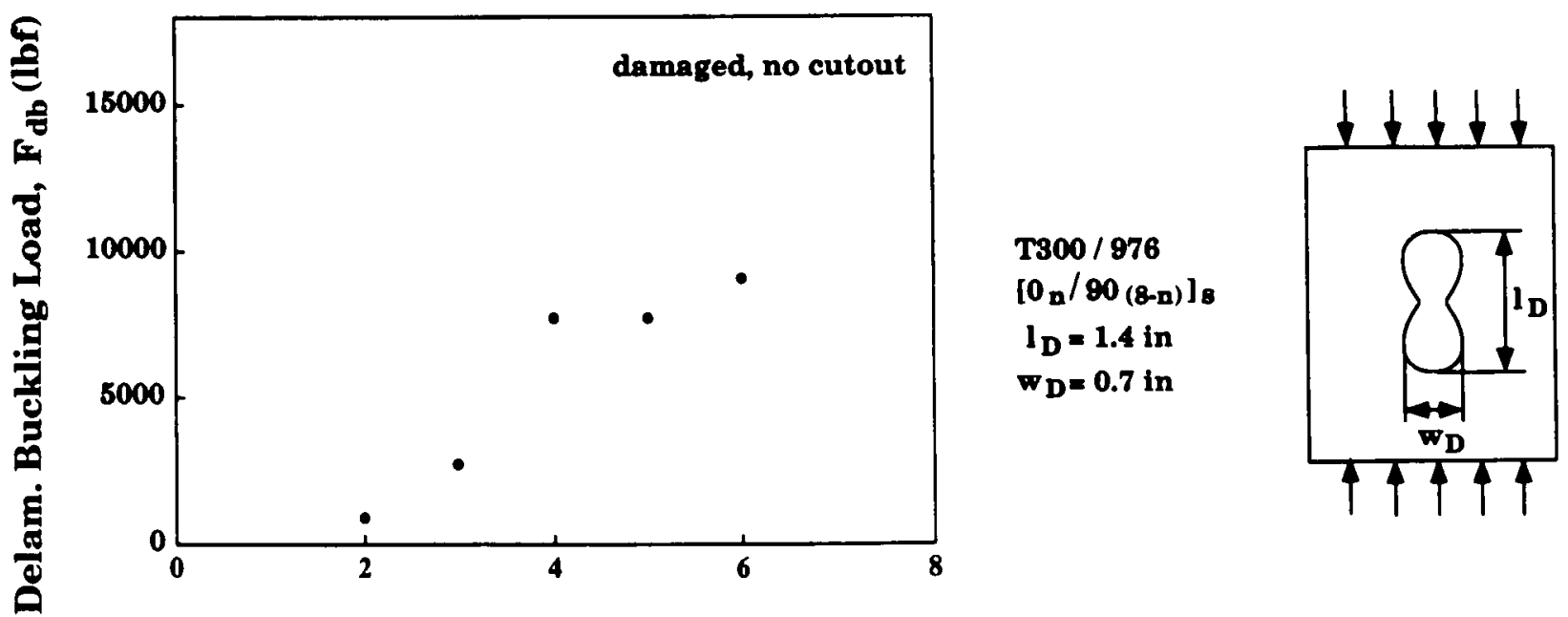

\section{Number of Plies in $0^{\circ}$ Ply Groups, $n$}

Figure 5. Delamination buckling load $\mathrm{F}_{\mathrm{db}}$ as a function of the number of plies $\mathrm{n}$ in the $0^{\circ}$ ply groups. Test section length $\mathrm{L}=3 \mathrm{in}$. 


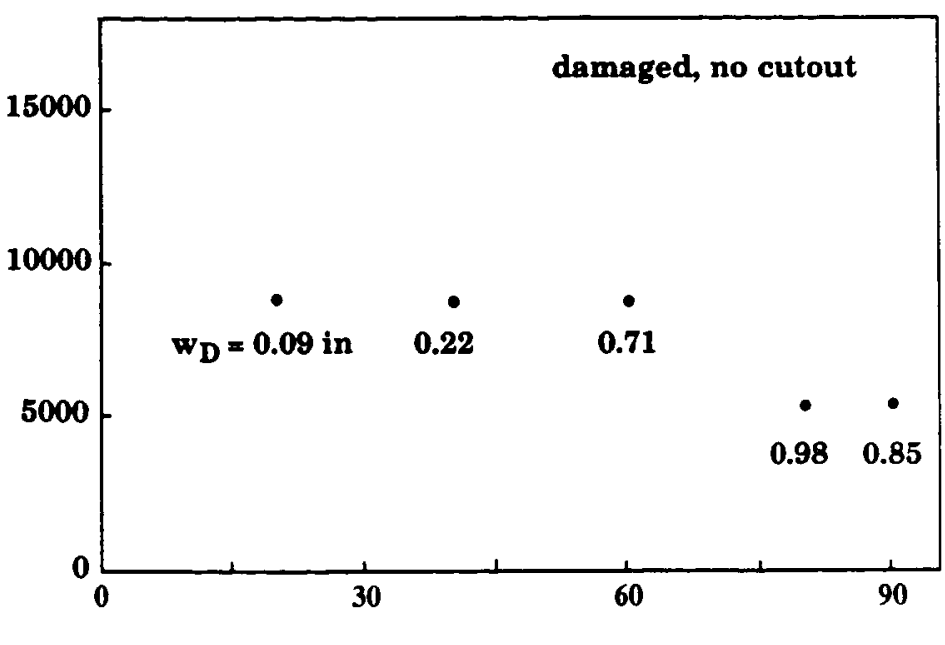

T300/976

$\left[0_{4} / \theta_{4}\right]_{\mathrm{s}}$

$l_{D}=1.5$ in

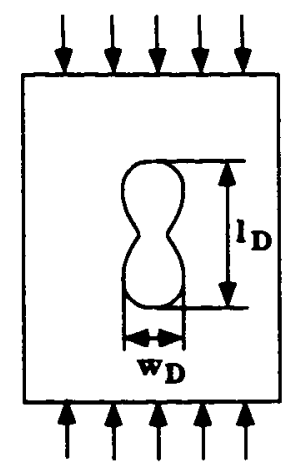

Mismatch Angle, $\theta$ (deg)

Figure 6. Delamination buckling load $\mathrm{F}_{\mathrm{db}}$ as a function of the mismatch angle $\theta$. Test section length $\mathrm{L}=3$ in.

0
0
0
0
0
0
0
0
0
0

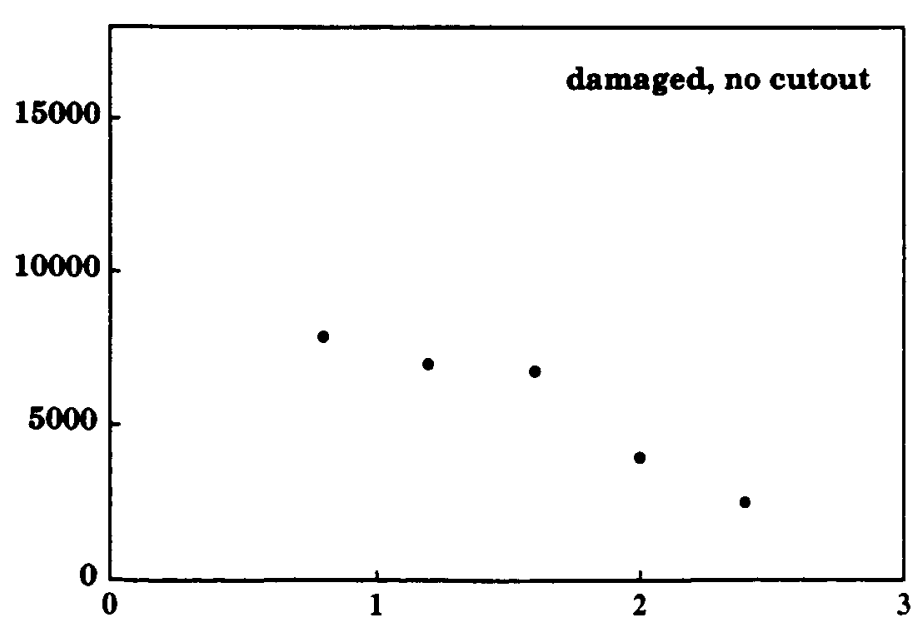

T300 / 976

$\left[0_{4} / 90_{4}\right]_{8}$

$w_{D}=0.5 l_{D}$

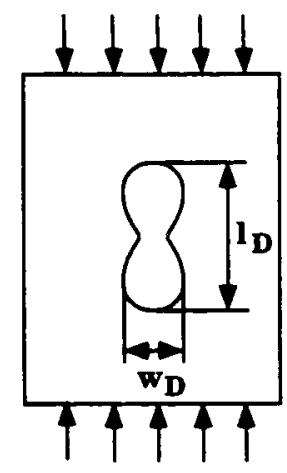

Delamination Length, $\mathbf{l}_{\mathrm{D}}$ (in)

Figure 7. Delamination buckling load $\mathrm{F}_{\mathrm{db}}$ as a function of the initial damaged zone length $l_{D}$. Test section length $\mathrm{L}=3$ in. 


\section{Damage Growth Load}

The damage growth load $\mathrm{F}_{\mathrm{g}}$ as a function of the number of plies $\mathrm{n}$ in the $0^{\circ}$ ply groups is shown in Figure 8. For damaged plates with no cutout, the growth load increased with the number of plies in the $0^{\circ}$ ply groups. To explain this trend it is again noted that the buckled sublaminate was at the back of the plate. Accordingly, an increase in the number of plies $n$ in the back $0^{\circ}$ ply group corresponded to an increase in the stiffness of the sublaminate and an increase in the delamination buckling load $\mathrm{F}_{\mathrm{db}}$ (Figure 5). For the plates with no cutout or repair, damage growth was always preceded by delamination buckling. Therefore, the damage growth load $\mathrm{F}_{\mathrm{g}}{ }^{\mathrm{nc}}$ also increased with increasing number of plies $n$ in the $0^{\circ}$ ply groups.

Cutting out the damage resulted in an increase in the damage growth loads $F_{\mathrm{g}}$ provided the back ply groups were relatively "thin" $(n=2,3)$. The reason for this is that removal of the damaged zone prevented delamination buckling and delayed damage growth. Furthermore, plates with $100 \%$ cutout had higher growth loads than those with $75 \%$ cutout because, in the latter case, not all the damaged zone was removed. Cutting out the damaged zone did not affect the damage growth loads $F_{g}$ of plates with "thick" back ply groups $(n=4-6)$. Because of the large back ply group thickness (corresponding to high stiffness of the sublaminate), in these plates, the damage started to grow even before the sublaminate buckled.
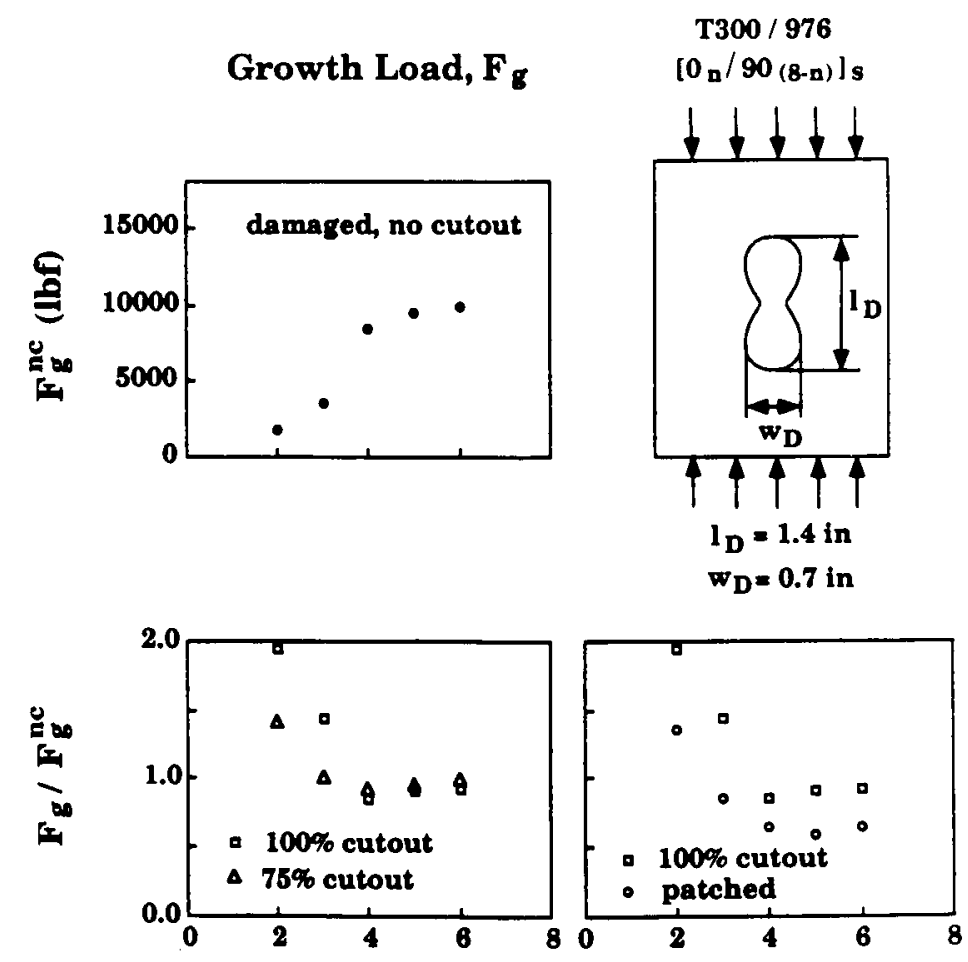

Number of Plies in $0^{\circ}$ Ply Groups, $n$

Figure 8. Damage growth load $\mathrm{F}_{\mathrm{g}}$ as a function of the number of plies $\mathrm{n}$ in the $0^{\circ}$ ply groups. Test section length $\mathrm{L}=3 \mathrm{in}$. 
Repaired plates had lower damage growth loads than plates with $100 \%$ cutouts (Figure 8, right). The reason for this is unclear, but it is likely that damage could initiate at the interface between the plate and the plug.

The damage growth load $\mathrm{Fg}_{\mathrm{g}}$ as a function of the mismatch angle $\mathrm{q}$ is shown in Figure 9. For damaged plates with no cutout, the growth load decreased as the mismatch angle increased (Figure 9, top). The reason for this decrease was that larger mismatch angles were accompanied by larger initial damaged zones (as was discussed in Section 3.1) and lower delamination buckling loads $\mathrm{F}_{\mathrm{db}}$ (Figure 6). Since the size of the damaged zone increased with increasing mismatch angle $\mathrm{q}$, the growth load $\mathrm{F}_{\mathrm{g}}{ }^{\mathrm{nc}}$ decreased. Neither removing the damaged zone nor repairing it had a significant effect on the damage growth loads, as shown in Figure 9, bottom.

The damage growth load $\mathrm{F}_{\mathrm{g}}$ as a function of the initial damaged zone length $\mathrm{l}_{\mathrm{D}}$ is shown in Figure 10. For plates with no cutout or repair, the damage growth load $\mathrm{F}_{\mathrm{g}}{ }^{\mathrm{nc}}$ decreased with the damage length $\mathrm{l}_{\mathrm{D}}$. Since the damage width $\mathrm{w}_{\mathrm{D}}$ increased along with the damage length, the overall size of the damaged zone increased. This increase in the size of the damaged zone resulted in the decrease in growth load $\mathrm{F}_{\mathrm{g}} \mathrm{nc}$.

For plates with relatively "small" initial damage lengths $\left(l_{D}<2\right.$ in), the damage started to grow before the sublaminate buckled. Hence, in this case, cutting out the damaged zone did not change significantly the damage growth load, i.e. the damage growth loads for plates with and without cutouts were nearly the same (Figure 10, middle). For plates with larger initial damage lengths $\left(l_{D} \geq 2\right.$ in), the sublaminate buckled, and this event governed the damage growth. In this case, cutting out the damaged zone resulted in an increase in the damage growth loads $\mathrm{F}_{\mathrm{g}}$. Repairing the plates seemed to produce little or no change in the growth load compared with plates with $100 \%$ cutout (Figure 10 , right).

\section{Buckling Load}

The global buckling load $\mathrm{F}_{\mathrm{b}}$ as a function of the number of plies $\mathrm{n}$ in the $0^{\circ}$ ply groups is shown in Figure 11. For initially undamaged plates, the buckling load $\mathrm{F}_{\mathrm{b}}{ }^{\circ}$ increased slightly as $\mathrm{n}$ (and hence the number of $0^{\circ}$ plies in the plate) increased. As the number of $0^{\circ}$ plies in the plate increased, so did the bending stiffness of the plate in the lengthwise direction. This resulted in an increase in the buckling load $\mathrm{F}_{\mathrm{b}}{ }^{\mathrm{o}}$.

As expected, damaged plates, with or without cutout, generally had lower buckling loads $F_{k}$ than undamaged plates. The removal of all or part of the damaged zone generally produced a small decrease in the buckling load compared to the buckling load of damaged plates with no cutout. Although the material in the damaged zone was not as strong as the undamaged material, it still provided some resistance to buckling. For this reason, removal of the damaged material caused a decrease in the buckling loads $\mathrm{F}_{\mathrm{b}}$.

Repaired plates had slightly higher buckling loads than plates with $100 \%$ cutout. However, repaired plates had practically the same buckling loads as damaged plates with no cutout. Inserting new material into the damaged zone provided more buckling resistance than a cutout, but not more than the original damaged material.

The global buckling load as a function of the mismatch angle $\mathrm{q}$ is shown in Figure 12. For initially undamaged plates, the buckling load $\mathrm{F}_{\mathrm{b}}{ }^{\mathrm{o}}$ exhibited a slight decrease with mismatch angle (Figure 12, top). As the angle q increased, the stiffness of the laminate in the lengthwise direction decreased leading to the decrease in the buckling load. 

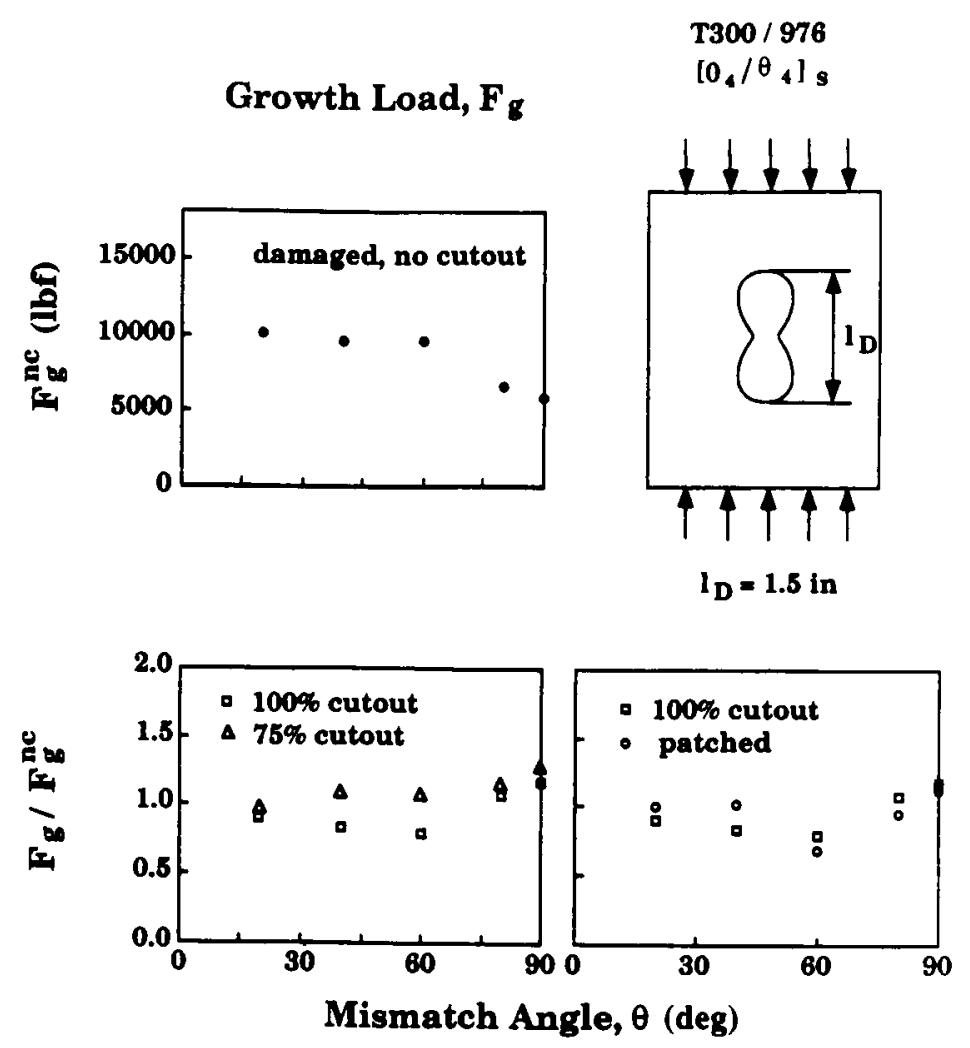

Figure 9. Damage growth load $\mathrm{F}_{\mathrm{g}}$ as a function of the mismatch angle $\theta$. Test section length $\mathrm{L}=3$ in.
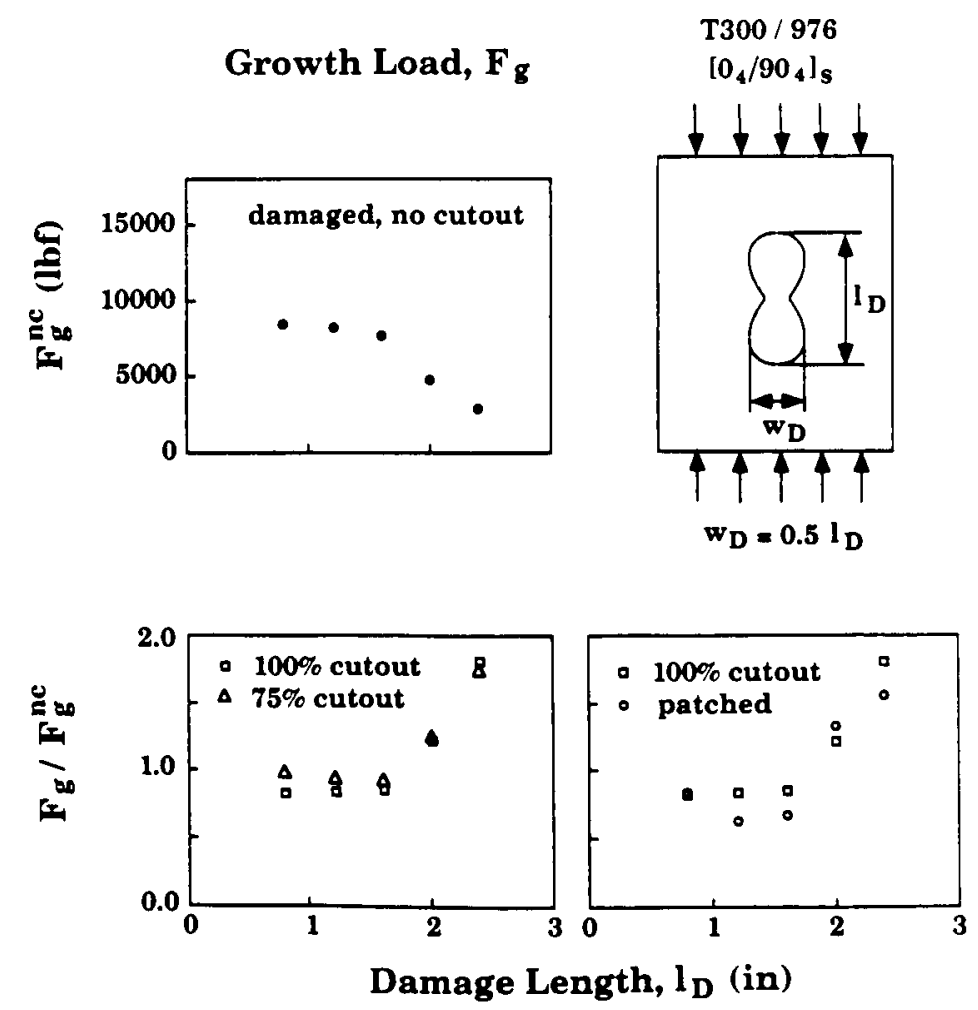

Figure 10. Damage growth load $\mathrm{F}_{\mathrm{g}}$ as a function of the initial damaged zone length $\mathrm{l}_{\mathrm{D}}$. Test section length $\mathrm{L}=3$ in. 

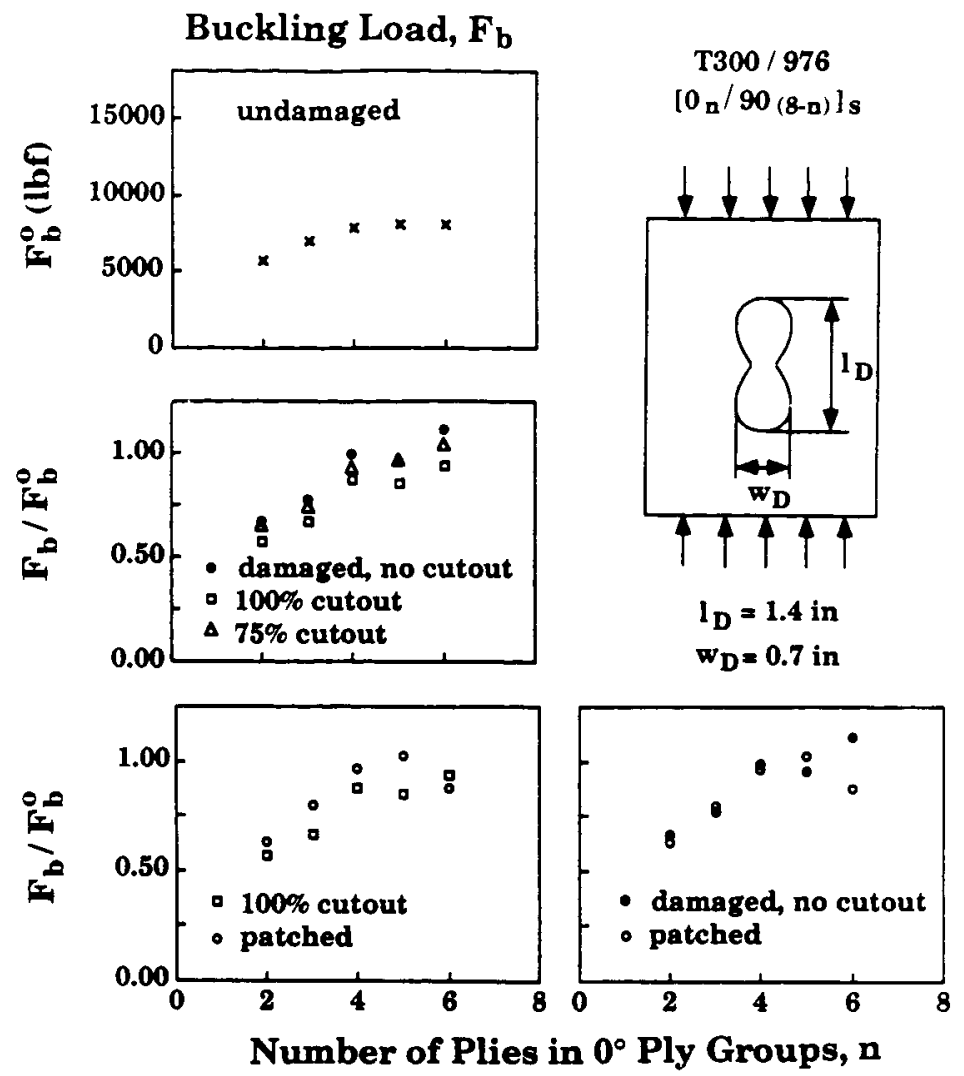

Figure 11. Buckling load $\mathrm{F}_{\mathrm{b}}$ as a function of the number of plies $\mathrm{n}$ in the $0^{\circ}$ ply groups. Test section length $\mathrm{L}=3$ in.

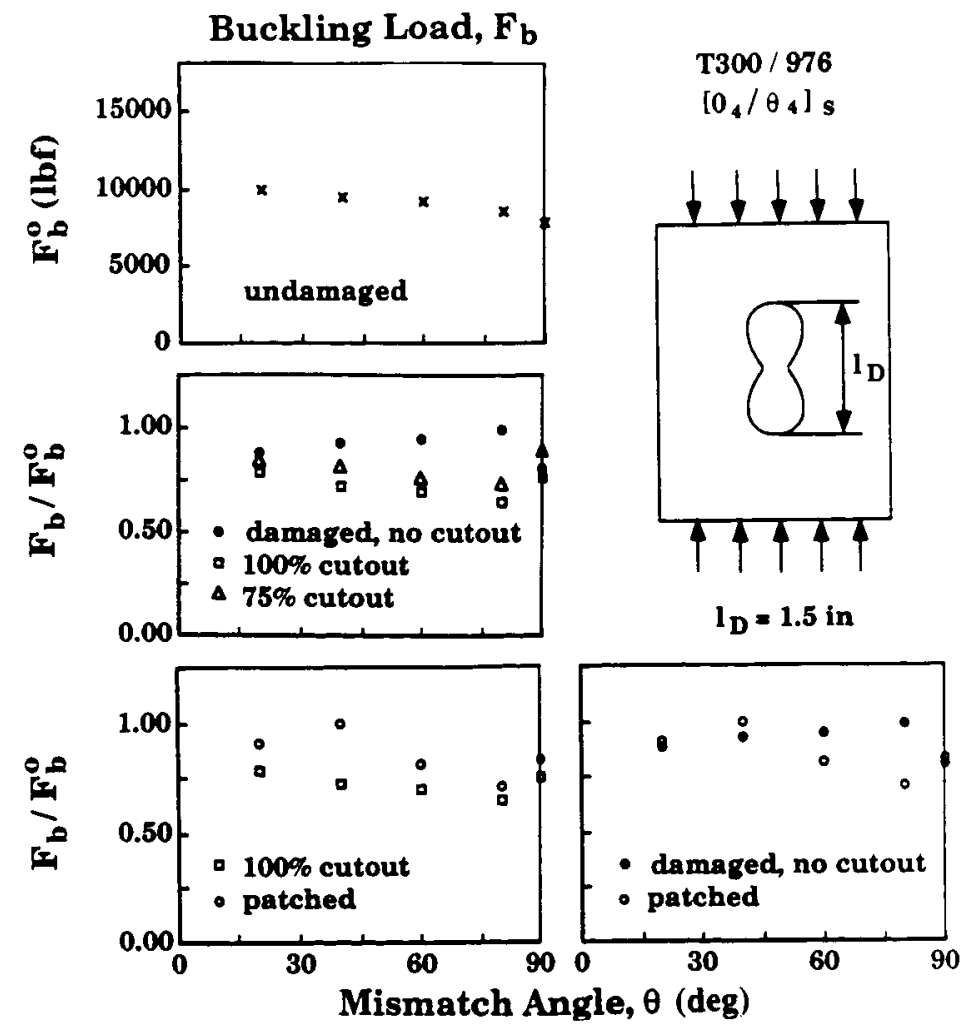

Figure 12. Buckling load $F_{b}$ as a function of the mismatch angle $\theta$. Test section length $\mathrm{L}=3$ in. 
Damaged plates with no cutout had lower buckling loads than undamaged plates $\left(\mathrm{F}_{\mathrm{b}} / \mathrm{F}_{\mathrm{b}}{ }^{0}<1\right)$, but higher buckling loads than plates with the damaged zone removed. Removal of the material, even though it was damaged, resulted in less resistance to plate buckling. Repaired plates had higher buckling loads $\mathrm{F}_{\mathrm{b}}$ than plates with a $100 \%$ cutout, but only about the same buckling loads as damaged plates with no cutout.

For damaged plates with and without cutouts, the buckling load $F_{b}$ decreased as the initial damaged zone length $l_{D}$ increased (Figure 13). Since the damage width $w_{D}$ increased with the damage length $l_{D}$, the size of the damaged zone also increased. This increase in the size of the damaged zone caused a decrease in the global buckling load $\mathrm{F}_{\mathrm{b}}$. Again, damaged plates without a cutout generally had higher buckling loads than the plates with either $100 \%$ or $75 \%$ cutouts.

Repaired plates had higher buckling loads than plates with $100 \%$ cutout but only about the same buckling loads as damaged plates with no cutout.

\section{Ultimate Load}

The ultimate load $F_{\mathbf{u}}$ as a function of the number of plies $n$ in the $0^{\circ}$ ply groups is shown in Figure 14. For initially undamaged plates, the ultimate load $\mathrm{F}_{\mathbf{u}}{ }^{\mathbf{0}}$ increased as $\mathrm{n}$ (and correspondingly, the number of $0^{\circ}$ plies in the plate) increased. There are two reasons for this trend. First, the plate buckling load $\mathrm{F}_{\mathrm{b}}$ increased with $\mathrm{n}$ (Figure 11), and higher buckling loads generally cause higher ultimate loads. Second, for a load applied in the lengthwise direction, a higher number of $0^{\circ}$ plies in the plates corresponds to a lower longitudinal stress in each ply. Since the ply stresses decreased with the number $\mathrm{n}$ of plies in the $0^{\circ}$ ply groups, the ultimate load $\mathrm{F}_{\mathrm{u}}{ }^{\circ}$ increased.

Damaged plates, of course, had lower ultimate loads than undamaged plates. Cutting out some or all of the damaged zone further reduced the ultimate loads. It is interesting to note that while, in general, cutting out the damaged zone increased the damage growth loads $\mathrm{F}_{\mathrm{g}}$ (Figure 8), it reduced the ultimate loads. Thus, cutting out the damaged zone may not always be advantageous.

Repaired plates had higher ultimate loads $\mathrm{F}_{\mathrm{u}}$ than plates with $100 \%$ cutout, but about the same ultimate loads as damaged plates with no cutout. Hence, repair does not seem to enhance the ultimate load.

The ultimate load $F_{u}$ is shown in Figure 15 as a function of the mismatch angle $q$. For undamaged plates, the ultimate load $\mathrm{F}_{\mathrm{u}}{ }^{\mathrm{o}}$ decreased with the mismatch angle. Again, there are two reasons for this decrease. First, the buckling load $\mathrm{F}_{\mathrm{b}}{ }^{\circ}$ decreased with mismatch angle (Figure 12). Lower buckling loads lead to a decrease in the ultimate load. Second, increasing the angle $q$ in the $\left[0_{4} / \mathrm{q}_{4}\right]$ s plates moved the fiber direction of the middle ply group farther out of alignment with respect to the applied axial load F. This resulted in higher longitudinal stresses for a given applied load, and hence to a decrease in the ultimate load $F_{u}$ with increasing mismatch angle $q$.

Damaged plates had lower ultimate loads $F_{u}$ than corresponding undamaged plates. Cutting out some or all of the damaged zone further reduced the ultimate loads, because cutouts decreased the buckling loads of the plates (Figure 12). Repair of the plates did not change significantly the ultimate loads $\mathrm{F}_{\mathrm{u}}$.

For damaged plates with no cutout, the ultimate load $F_{u}$ decreased as the initial damaged zone length $l_{D}$ increased for all three materials (Figure 16). Since the damage width $w_{D}$ increased with the damage length $l_{D}$, the overall size of the damaged zone also increased. The increase in the size of the 


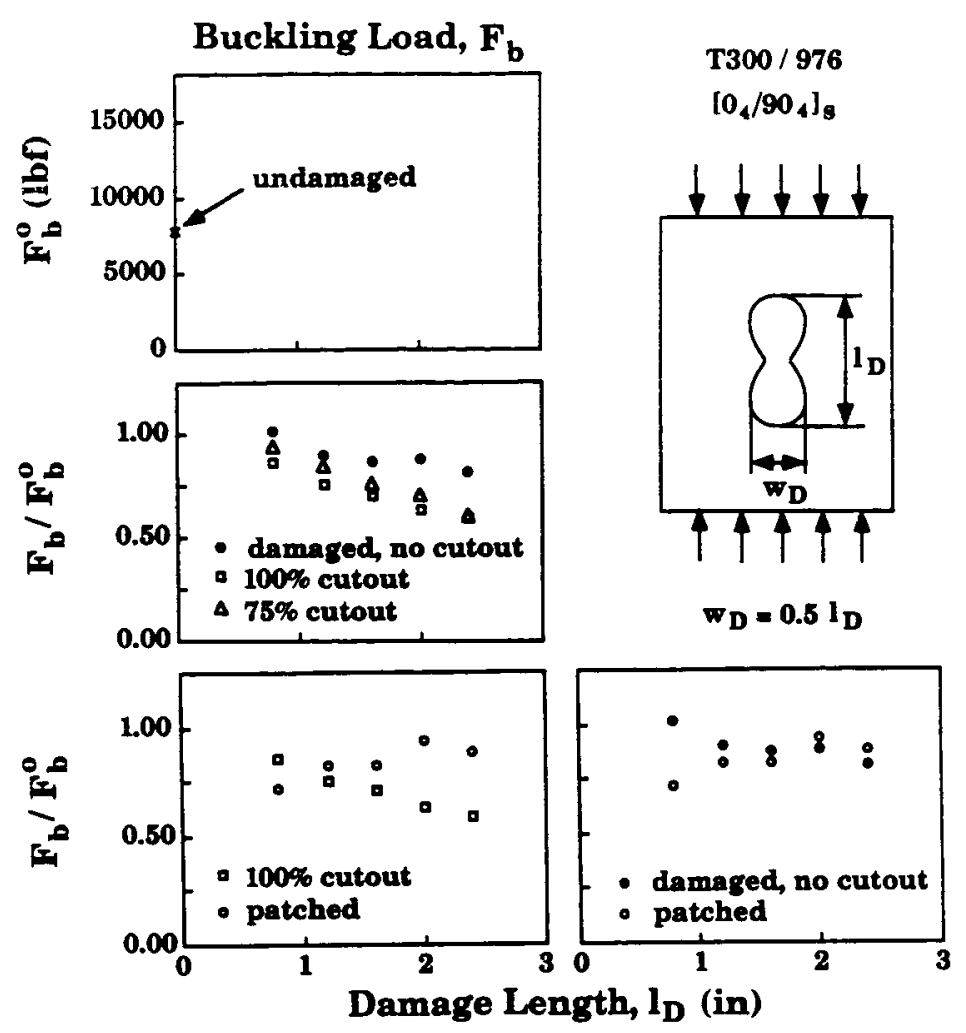

Figure 13. Buckling load $F_{b}$ as a function of the initial damaged zone length $l_{D}$ for T300/976 graphite/epoxy. Test section length $L=3$ in.

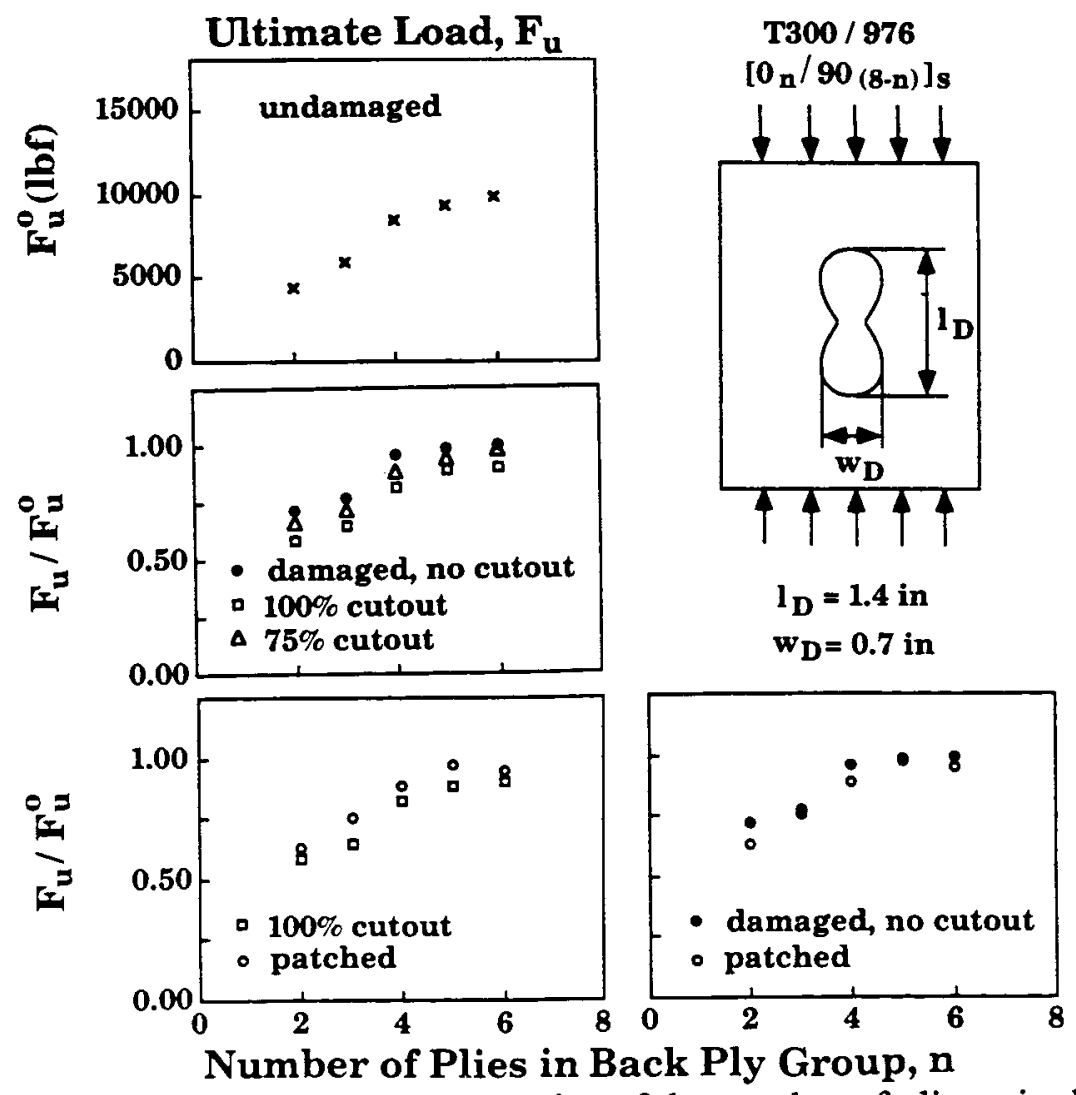

Figure 14. Ultimate load $F_{u}$ as a function of the number of plies $n$ in the $0^{\circ}$ ply groups. Test section length $\mathrm{L}=3$ in. 

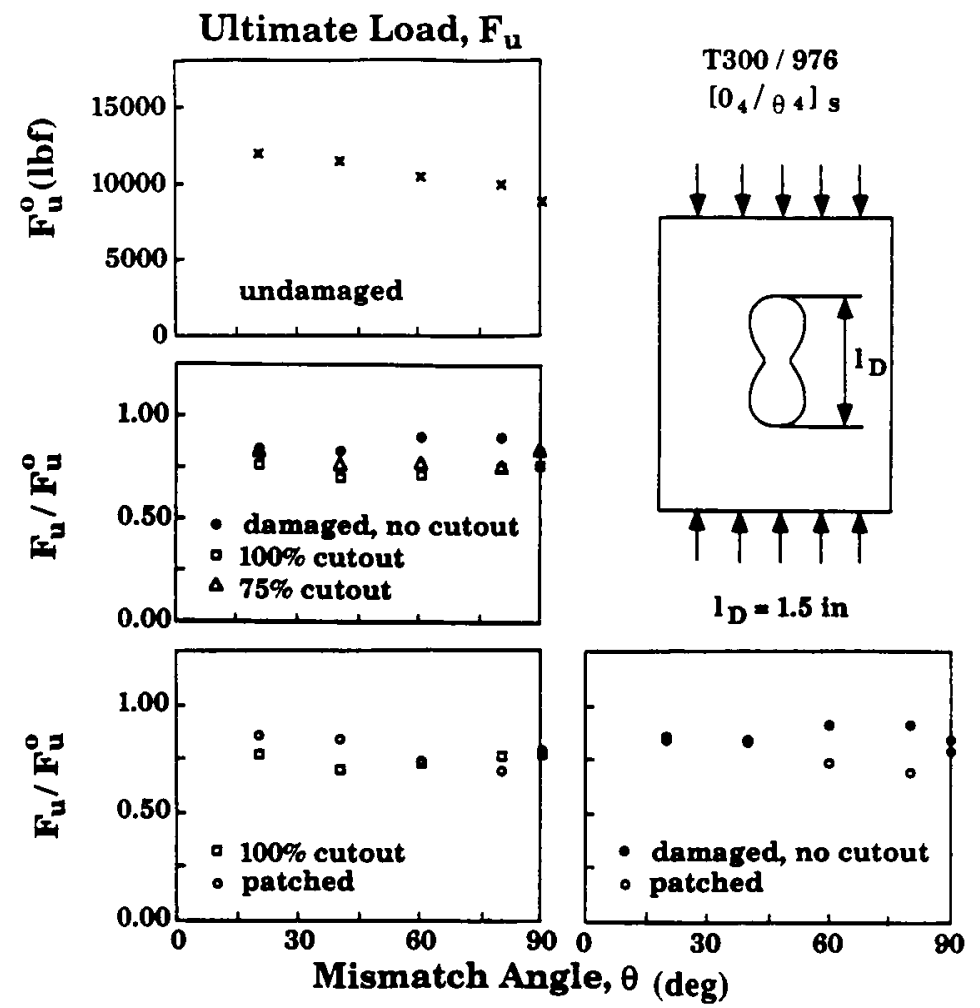

Figure 15. Ultimate load $F_{u}$ as a function of the mismatch angle $\theta$. Test section length $\mathrm{L}=3$ in.
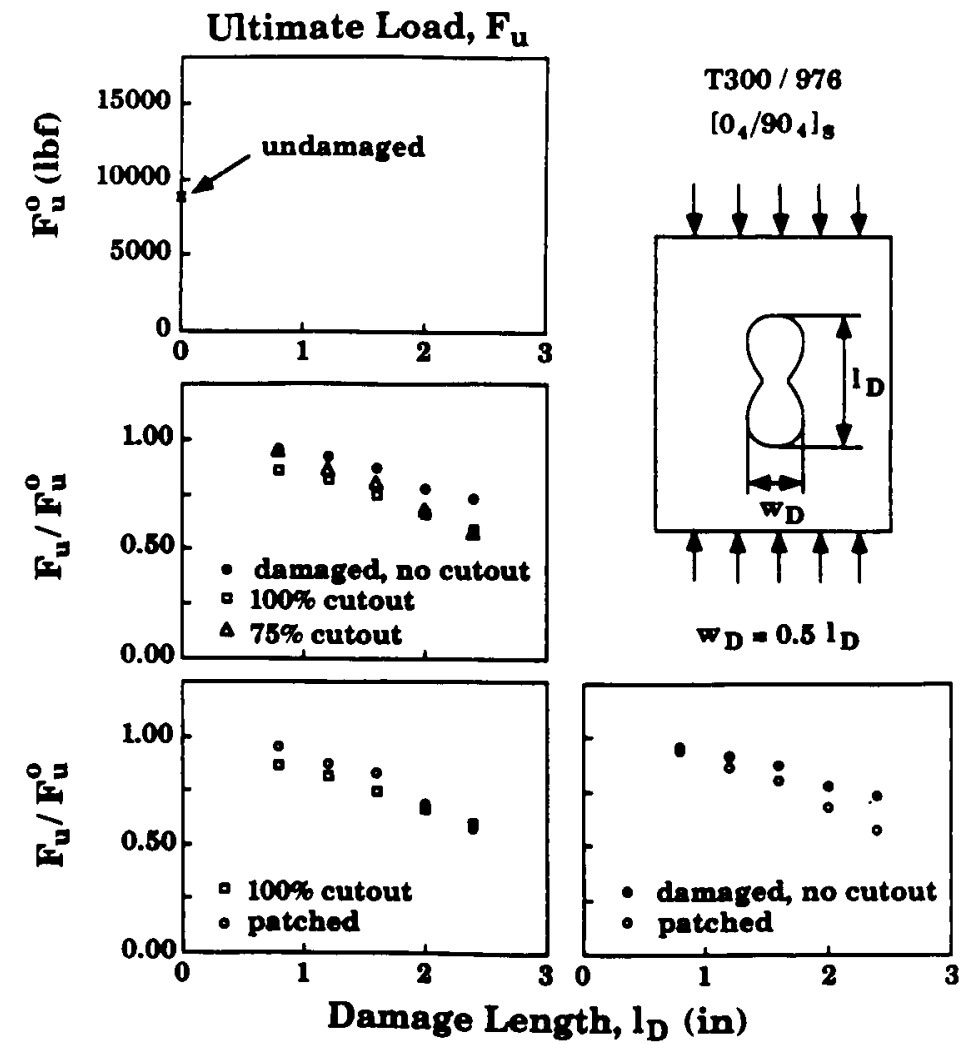

Figure 16. Ultimate load $F_{u}$ as a function of the initial damaged zone length $l_{D}$ for T300/976 graphite/epoxy. Test section length $L=3$ in. 
damaged zone caused a decrease in the ultimate load $\mathrm{F}_{\mathrm{u}}$. For all three materials, the removal of part or all of the damaged zone resulted in the plates having lower ultimate loads $F_{u}$ than damaged plates with no cutout.

Repaired plates had slightly higher ultimate loads $\mathrm{F}_{\mathrm{u}}$ than plates with $100 \%$ cutout. However, repaired plates had lower ultimate loads than damaged plates with no cutout.

\section{CONCLUDING REMARKS}

The data presented in this paper provide information regarding the in-plane compressive strengths of damaged plates.. In general, the compressive strength was further reduced if all or part of the damaged zone was removed. Repairing the damaged plates, by cutting out the damaged zone and replacing it with a plug, did not necessarily improve the compressive strength of a plate. In most cases, the highest compressive strength was retained if the damaged zoñe wầ simply left in the plate. Care should be exercised in extending the results to sandwich panels.

\section{ACKNOWLEDGMENTS}

This work was supported by NASA Langley Research Center under contract number NAS118778, with Mr. C.C. Poe acting as the project engineer. Messrs. Y.F. He and H.J. Lee assisted with tests. 